\title{
Sustainability science education: our animalistic response-ability
}

\author{
Kathryn M. Bateman ${ }^{1} \cdot$ David Steele $^{2} \cdot$ Chelsea M. Sexton $^{3}$
}

Received: 8 November 2020 / Accepted: 21 January 2021 / Published online: 8 July 2021

(c) The Author(s), under exclusive licence to Springer Nature B.V. 2021

\begin{abstract}
In this paper, we craft a dialogue between "The Anthropocene as we know it: posthumanism, science education and scientific literacy as a path to sustainability," by Sophia Jeong, Brandon Sherman, and Deborah Tippins and, "The quest for sustainable futures: designing transformative spaces for youth through critical response-ability," by Shakhnoza Kayumova and Deborah Tippins. We argue for an optimistic approach to post-Anthropocene science education that acknowledges humans as the animals we are, albeit with a more sophisticated understanding of our place in the world. It is this understanding that gives us both responsibility and a response-ability to our human and non-human actors within our earthly entanglement. To do this requires reimagining science classrooms as locations of opportunity where students develop agential literacy. These classrooms provide an environment that allow students to develop their skills as sustainability engineers. We advocate for embracing indigenous ways of knowing, opening locations of possibilities through policy reform, fostering an integrated model of STEM education, and re-imagining teacher education to promote and move toward equitable science education.
\end{abstract}

This manuscript is part of the special issue contemplative inquiry, wellbeing and science education, guest edited by Kenneth Tobin.

The authors express their gratitude to María Esther Téllez-Acosta for the Spanish abstract translation and Sergej Udarcev for the German abstract translation.

Lead Editor: K. Tobin.

Kathryn M. Bateman

kathryn.bateman@temple.edu

David Steele

dsteele@aldergse.edu

Chelsea M. Sexton

cmsexton@uga.edu

1 Department of Psychology, Temple University, 1701 N. 13th Street, 333 Weiss Hall, Philadelphia, PA, USA

2 Alder Graduate School of Education, Redwood City, CA, USA

3 Department of Mathematics and Science Education, University of Georgia, Athens, GA, USA 
Keywords Agential literacy $\cdot$ Sustainability $\cdot$ Posthumanism $\cdot$ Post-Anthropocene $\cdot$ Science education · Equity

\section{Resumen}

En este artículo, elaboramos un diálogo entre "El Antropoceno como lo conocemos: posthumanismo, educación en ciencias y alfabetización científica como un camino hacia la sostenibilidad", según Sophia Jeong, Brandon Sherman y Deborah Tippins y, "La búsqueda de futuros sostenibles: diseñando espacios transformadores para los jóvenes a través de la capacidad de respuesta crítica", según Shakhnoza Kayumova y Deborah Tippins. Discutimos un enfoque optimista de la educación en ciencias post-antropoceno que reconozca a los humanos como los animales que somos, aunque con una comprensión más sofisticada de nuestro lugar en el mundo. Dicha comprensión es la que nos da tanto responsabilidad como capacidad de respuesta frente a los actores humanos y no humanos dentro de nuestro entrelazamiento terrenal. Hacer esto requiere reinventar las aulas de ciencias como lugares de oportunidad donde los estudiantes desarrollan una alfabetización activa. Estas aulas proporcionan un entorno que permite a los estudiantes desarrollar sus habilidades como ingenieros de la sostenibilidad. Abogamos por adoptar las formas de saber indígenas, abriendo espacios de posibilidades a través de reformas políticas, fomentando un modelo integrado de educación STEM y reinventando la formación docente para promover y avanzar hacia una educación en ciencias equitativa.

\section{Zusammenfassun}

In diesem Beitrag entwickeln wir einen Dialog zwischen "Das Anthropozän, wie wir es kennen: Posthumanismus, naturwissenschaftliche Bildung und scientific literacy als Weg zur Nachhaltigkeit" von Sophia Jeong, Brandon Sherman und Deborah Tippins und "Die Suche nach einer nachhaltigen Zukunft: Gestaltung von transformativen Räumen für Jugendliche durch kritische Reaktionsfähigkeit" von Shakhnoza Kayumova und Deborah Tippins. Wir plädieren für eine optimistische Herangehensweise an die post-anthropozäne naturwissenschaftliche Bildung, die den Menschen als das Tier anerkennt, das er ist, wenn auch mit einem differenzierteren Verständnis für unseren Platz in der Welt. Es ist dieses Verständnis, das uns sowohl die Verantwortung als auch die Fähigkeit zur Reaktion auf unsere menschlichen und nicht-menschlichen Akteure innerhalb unserer irdischen Verstrickung gibt. Um dies zu erreichen, ist es notwendig, den naturwissenschaftlichen Unterricht als Ort der Möglichkeiten neu zu gestalten, an dem die Schüler*innen Handlungskompetenz entwickeln. Diese Klassenzimmer bieten eine Umgebung, die es den Schülerinnen und Schülern ermöglicht, ihre Fähigkeiten als Nachhaltigkeitsingenieure*innen zu entwickeln. Wir plädieren dafür, indigene Wissensweisen zu berücksichtigen, Orte der Möglichkeiten durch politische Reformen zu eröffnen, ein integriertes Modell der MINT-Bildung zu fördern und die Ausbildung von Lehrer*innen neu zu gestalten, um eine gerechte wissenschaftliche Bildung zu fördern und zu erreichen.

The impact of human activity on the world and all its inhabitants has reached a critical point. There are increasing amounts of evidence, both qualitative and quantitative, that expose the increased vulnerability our cultural and ecological commons are showing in response to anthropogenic impacts such as climate change, habitat fragmentation, and food and water insecurity (Thompson and Tippins 2013). 
Although there is insurmountable evidence that humans negatively impact climate change, we still are inundated with messages from climate change deniers. While this tension exists for a multitude of reasons, many blame a basic lack of understanding of scientific processes and scientific knowledge by the general public (Jeong, King, Pauli, Sell, and Steele 2020). These short-sighted misunderstandings have been exacerbated by the elimination of environmental protections that were signed into law as a means to curb or slow down human impact. In the United States, these decisions-ranging from withdrawing from the Paris Agreement to attacking clean energy resources-have re-centered humans, and, more specifically, centered capitalism as the core of sustainability efforts (Jeong, Britton, Haverkos, Kutner, Shume, and Tippins 2018). These types of actions continue to accelerate what has been described as an inevitable causal chain that will alter the world in cataclysmic ways (Lovelock 2015). This begs the question, "What now?" Do we as a species continue down our current path without much care or thought to our impending doom? Or do we increase sustainability efforts, such as eating less meat, producing less trash, or taking a walk instead of a mechanical mode of transportation, to slow the impacts of human activity on the world? Or has our past exploitation of nature reached a point for "new, grand thoughts to emerge"? (Jeong, Sherman, \& Tippins 2021).

Jeong, Sherman, \& Tippins (2021) believe the solution lies in humans repositioning ourselves and our relationship with the world. They argue that we must shift from seeing the world through a human-nature dualistic lens to one that recognizes humans as interrelated entities connected through a process of intra-action (Jeong, Sherman, \& Tippins 2021). Karen Barad describes "intra-action" as a concept that "signifies the mutual constitution of entangled agencies... [that] don't exist as individual elements" (2007, p. 33). The idea of "intra-action," a central concept of her agential realist theory, is further conceptualized through the idea of entanglement, which she describes as lacking "an independent, selfcontained existence," because one cannot exist as a separate entity, but one can only exist through the intra-actions with one's surrounding life and matter (Barad 2007, p. ix). Once the interwoven textile of entanglement is understood, "scientific literacy becomes a matter of agential literacy of learning how to intra-act responsibly within the world" (Barad 2000, p. 237, original emphasis). This type of thinking requires a seismic paradigm shift in the mindset of humans that we do not view as attainable, especially in the near future. We do, however, believe that we can use human ingenuity to make incremental shifts and changes that might allow us to avoid a posthuman, post-Anthropocene epoch. In doing so, these shifts might also help us to see the entangled world in which we already live, a world in which humans see ourselves as part of nature and not separate from it.

Here, we argue that humans are at the center of sustainability, whether from a humanistic lens or a posthuman one. Because we believe that humans need to see entanglement with multi-species (including humans, more-than-humans, and matter of all kinds), and design solutions to mitigate our impact on the world, we firmly place humans at the center of this work. As conscious beings, any attempt to decenter human agency ignores the responsibility that humans must take in making a conscious decision to see this entanglement and assumes that this mindset could be of an innate, unconscious nature.

In the following sections, we provide additional commentary as a robust response to the previous authors' works. Our goal is to have dialogue between the two papers as a means to enact what Ken Tobin described as, "Dialectical relations that crack us open to produce what we knew before, as well as something different," (oral communication). In doing so, we hope to make clear our position of humans as entangled beings whose behavior is not unlike other organisms; to discuss new levers of scientific literacy using agential literacy as a framework to transform humans from ecosystem engineers to sustainability engineers; 
and to highlight issues of equity within sustainability efforts. We begin by discussing the actions of human beings as animals invested in survival and how this complicates a postAnthropogenic approach to science education. We then describe the shifts from science literacy to agential literacy to position students as sustainability engineers within locations of possibility. We problematize current approaches to sustainability movements from an educational equity standpoint and provide disruptions to the current framework of education that can further open locations of possibility, (Brandt 2008) for students from marginalized communities to gain response-ability, (Kayumova and Tippins 2021) as sustainability engineers.

\section{Humans as animals in survival mode}

A post-humanist approach de-centers humans and human agency, shifting our thinking from assuming humanity as the primary reference point in understanding the world toward a consideration of communal living between humans and non-humans (Jeong, King, Pauli, Sell, and Steele 2020). Even as philosophical approaches to science education shift toward sustainable efforts that fully realize human intra-action and entanglement with nature, we also acknowledge the human capacity to act and think metacognitively as valuable attributes in human culture. We do not believe that these two frameworks must live outside of each other but can coexist in a way in which humans recognize our entanglement as part of nature while still being mindful of our power to create, shape, and mold our world through empathy and technology. In fact, as we demonstrate below by providing an example of changes that bald eagles made to their eating habits out of necessity, the behavior of entangled beings is similar to that of humans in their ability to manipulate and use resources as needed.

Davidson and Gray (2018) describe changes to a food web in the Aleutian Island coastal regions of Alaska that saw precipitous declines in sea otter populations throughout the 1990s. As carnivorous sea otter populations declined, kelp forests in the Aleutian Island region also began to disappear at alarming rates. Simultaneously, the diet of the bald eagle diet in the Aleutian Islands region underwent significant shifts due to declining fish population. Bald eagles, opportunistic feeders, proved a more resilient species than sea otters as the resources in their habitat and ecosystem became limited. With a reduction in their primary food source (marine fish), bald eagles pivoted to an alternative food source-seabirds nesting in the cliffside regions of the Aleutian Islands. Bald eagle population numbers and birth rates increased, despite the dwindling of their historic food supply. We see here an example of entanglement-living and nonliving actors intra-acting in the ecosystem.

Individual survival and population sizes depend on relationships within the entanglement, including predation, availability of resources, and parameters of the physical environment (light, temperature, space for shelter and reproduction). The Aleutian Island ecosystem example shows how these entanglements manifest in the transfer of matter and energy, as organisms obtain energy through interactions and relationships within a particular food web. These complex food webs serve as a basis for understanding the dynamic entanglement between living, more-than-living, and non-living beings. Computer simulations, often grounded in the Loktak-Volterra Model, illustrate the concept that living organisms utilize resources to maximize their species population (Berryman 1992). Humans are 
not outside of this model but act within it, already entangled, intertwined in a back-andforth dance as organism and environment (Roth 2019).

While we recognize our entanglement as part of nature, there are certain qualities of human culture that contribute to the continued perpetuation of a nature-culture dualism, where human distinctiveness defines the natural (Biersack 2006, p. 4). One such distinction is our ability to create and use technology to protect and prolong human life. Technological advances, from as simple as fire to as complex as nanotechnology, provide humans an advantage - the ability to exploit a diversified range of resources (i.e., habitat, energy). Here, humans become ecosystem engineers. Barad (2007) argues that humans simply made a habit of celebrating biomimicry technology that nature has been perfecting for millennia; however, we contend this ingenuity is distinctive to humans as efficient ecosystem engineers. We recognize that from this ingenuity has emerged an abundance of negative anthropogenic impacts to the living and non-living actors that coexist in an entanglement, forcing us to re-examine and reimagine our place in the world. Humans must now reframe our positionality in our entanglement with the other actors in our world.

\section{Humans as sustainability engineers}

Human and more-than-human actors have taken on the role of ecosystem engineer organically throughout time, but we need to move into more critical, agential roles. Ecologists classify a subset of organisms as ecosystem engineers-those that create, modify, and maintain their habitats. For example, a classic ecosystem engineer is a beaver that chews through trees upstream of its home to make a dam. In creating this dam, the beaver fashions a dry lodge in which to stay warm and dry and a pond that creates a slow-moving water habitat. This pond creates a habitat for the aquatic plants in a beaver's diet. By crafting this altered ecosystem, the beaver eliminates space for some organisms but engineers a suitable habitat for others.

Humans undertook the role of ecosystem engineers as early as the agricultural revolution (circa 12,000 years ago). Humans have changed forests into agricultural grasslands and later into urban centers of asphalt and concrete. As animals, we have acted in the supposed interest of our species, following Cartesian "othering" as we make a habitat that is pleasing to ourselves without considering the more-than-human entities interacting in entanglement. Having the metacognitive tools to choose to consider (or not) the multi-species in our decision-making, we also can choose to be sustainability engineers who recognize our entanglement instead of simply continuing to exist as ecosystem-engineering masters.

While other organisms play crucial roles, only humans make a conscious decision to enter into a sustainable entanglement. Pollinators, bats, birds, and bees keep primary producers genetically vibrant and stable amidst challenges such as insect and fungal pests and a changing climate. These organisms exist in long-developed co-evolution symbioses; many in obligate mutualisms where they must continue their "sustainability job" for survival of the individual species. Fungi break down materials into their molecular components so they can be recycled, but do not ponder if a fern will enjoy the phosphate released into the soil. Hummingbirds do not decide to pollinate flowers. Sharks do not think about the desire of the fish they consume. They are entangled but unaware of it. Their only goal is to survive long enough to successfully reproduce. Humans' ability to mold the environment to fit our needs diminishes our connection to nature. We have lost our ability to coexist in the entanglement, to understand the importance of the mutual relations of the intra-actions. 
As the climate crisis moves toward a point of no return, humans must reestablish this connection. We need to decide to live and prosper in a way that benefits the multi-species, instead of just our own kind, to live sustainably as entangled beings. This decision centers us as cognizant beings, rather than a species just acting in our own interest.

Consciousness of entanglement and the decision to help the multi-species thrive moves humans into the role of sustainability engineer, a role not held by other organisms. To make the switch from ecosystem engineer to sustainability engineer, we must employ both Barad's (2001) idea of agential realism and Jeong, Sherman and Tippins' (2021) idea of agential literacy to provide a path for humans to reimagine ourselves. We have the cognition to reconfigure our species away from engineering ecosystems to fit our needs, and instead, engineer sustainable solutions to make our needs fit what our entanglement has to offer with respect to intra- and inter-generational equity. By tapping into and developing agential literacy within the human species, we can make that transformation.

\section{Agential literacy education for sustainability}

Using agential literacy as a tool to shift humans from their role of ecological engineers to sustainability engineers of the entanglement has powerful possibilities. While some may posit agency as linked to empowerment, Kayumova and Tippins (2021) move to problematize empowerment because of the histories and connotations associated with the concept. They view empowerment as a problem that relates to entanglement and agential literacy. Key words in common definitions of empowerment: "self;" "human;" and "control;" represent ideas that go against Barad's ideas of entanglement. For Barad, empowering a person or a group implies that they did not have power until it was given to them. By viewing science education and sustainability education with a lens of post-humanism, the idea of power emanates from intra-action in the entanglement and the relationships within (Jeong, Sherman, \& Tippins 2021), rather than an exterior source. Achieving this balance does not come from the traditional empowerment of fighting colonial anthropocentric dualisms, but is realized through the ability to respond, which reframes empowerment as a critical response-ability (Kayumova and Tippins 2021). Mindful of our response-ability of the intra-actions within the entanglement, we can build agential literacy to become sustainability engineers.

Within this issue, Jeong and colleagues call for transformative science education practices that improve human understanding of our entanglement with the more-than-human through agential literacy. Barad (2000) asserts that "agency cannot be designated as an attribute," as it is "about the possibilities and accountability entailed in reconfiguring" the intra-actions of the entanglement (p. 236). When using Barad's definition, it can be difficult to imagine how to teach agential literacy in a science classroom-agency is not a tangible object or skill to be taught, but a becoming as a result of multi-species interactions. In relation to this issue, Kayumova and Tippins (2021) describe ways the science education community can facilitate the becoming of science students into agential literates in informal learning spaces. They recognize these locations of possibility (Brandt 2008) for agential literacy are built through critical response-ability in science education. Only by acknowledging that we are entangled with multispecies and each other will we achieve a post-Anthropocene epoch with favorable outcomes for us and the more-than-us. True embracement of these intra-actions means recognizing and elevating all humans and 
non-humans to equal places within the entanglement that is sustainability regardless of their status or location.

\section{Impacts of sustainability are equity issues}

If we are to counterbalance the animalistic instincts of humanity to preserve our survival, education needs to serve as a mediator to develop agential literacy. However, education is not provided equitably to all students and communities. For science education to help humans see our place in the sustainability entanglement, we need to address the inequities in science education and the related environmental impacts on communities. Communities most often underserved in science education are those in urban centers, with BIPOC (Black, Indigenous, and people of color) populations and high levels of poverty. Kayumova and Tippins (2021) describe ways that they have addressed the need to empower BIPOC student populations in STEM education, but situate their work in non-school settings, where the tight grip of neo-liberal educational policies has less control over the day-to-day workings of science teaching and learning. In this section, we explore ways in which informal community-grounded environmental justice has worked in an urban community (e.g., Hunting Park in Philadelphia) and the facets of the community that continue to fail to position students to develop the agential literacy necessary to become sustainability engineers.

As a result of U.S. education policies such as the Every Student Succeeds Act (ESSA) and its predecessor, No Child Left Behind (NCLB), schools serving non-dominant communities are more likely to be labeled as "failing" by quantitative metrics (standardized tests, graduation, and attendance rates; Darling-Hammond 2007). In the wake of NCLB, researchers documented decreases in the amount of time spent teaching science (Au 2011) in order to afford a focus on reading and math (Anderson 2012); a narrowing of science curricula (Au 2011); shifts away from reform-based science education practices in favor of test preparation (Southerland, Smith, Sowell, and Kittleson 2007); and reductions in resources for teaching science (Spillane, Diamond, Walker, Halverson, and Jita 2001). How, if school-based science does not have time, resources, or the positions of privilege afforded to math and reading, can urban minority communities establish the science literacy and agential literacy needed to navigate a post-Anthropocene position as sustainability engineers?

Informal education, such as afterschool programming, museums, and community organizations can serve as a starting ground for urban non-dominant communities to learn about and enact agential literacy. As Kayumova and Tippins (2021) discuss, students can be brought into the work of "response-ability" for sustainability as they become entangled in the environmental justice work of air quality or fracking within an informal science camp. However, we must also recognize that these students are parts of larger entanglements as they move through their schools, communities, family units, and larger cultures to interact with the world around them. It is not only students who need to see their entanglement, but the other agents within those same entanglements-parents, teachers, community leaders and organizers, government officials, etc.

To ground these ideas in a living context, we move our lens to the city of Philadelphia's Hunting Park neighborhood. Philadelphia has been studied extensively for both its climate injustice (i.e., urban heat islands; Hondula et al. 2012) and its historically inequitable housing policies (i.e., redlining; Hillier 2003). Hunting Park is located in the northern section of Philadelphia with just under 30,000 culturally and linguistically diverse residents 
(56\% Latinx, 46\% black; 46\% Spanish speaking), the majority of whom live below the poverty line (Philadelphia Office of Sustainability 2019). Historically, Hunting Park has been entangled in racist housing policies. Like other urban communities populated predominantly by BIPOC, homes in Hunting Park were red or yellow lined in the 1930s and 1940s under the Home Owners Loan Corporation Act (HOLC). This HOLC designation labeled homes and neighborhoods as "hazardous" and a high risk for loan companies, thus making loans in these areas difficult to obtain by the recent immigrants and minorities who inhabited rental units in the area.

Beyond economic justice, physical health is also part of the entanglement of injustice experienced by urban BIPOC communities. Within the Hunting Park neighborhood, for example, childhood asthma (Philadelphia Office of Sustainability 2019) is the highest in the city (an indicator of poor air quality) and extreme heat events are increasing yearly. From 1980-2013, extreme heat events rose from four days per year to twelve days per year in urban settings but only from four to five days per year in non-urban settings (Weber, Sadoff, Zell, and de Sherbinin, 2015). Using data from 1986-2008 Hondula, Davis, Leisten, Saha, Veazey, and Wegner (2012) demonstrated how extreme-heat events are a life-or-death issue in Philadelphia, particularly in places like Hunting Park. High-density housing areas populated by low-income, elderly residents experience higher surface temperatures and, subsequently, more heat-related deaths than analogs in communities with higher income averages throughout the city.

Increased green space, trees, parks, and laws, can mitigate the heat island impacts of a city's concrete expanses. However, when those green spaces are isolated from the lived spaces, such as the existence of a nearby park, but an absence of trees on residential streets, green spaces are ineffective at combating the heat (Hondula, Davis, Leisten, Saha, Veazey, and Wegner 2012). Such is the case for Hunting Park. In the 1.69 square miles of Hunting Park, there is an 87 -acre park, but $76 \%$ of the neighborhood is made up of buildings and paved surfaces, compared to $52 \%$ in the city of Philadelphia as a whole. This lack of integrated green space is common among neighborhoods that formerly fell into the HOLC's red and yellow lined categories (Locke, Hall, Grove, Pickett, Ogden, Aoki, Boone, and O’Neil-Dunne 2020).

In addition to environmental injustice, schools in Hunting Park face similar educational injustices as part of its entanglement. Neighborhood public schools serving Hunting Park (three public elementary schools, one public middle school, and one public high school) report scores well below state averages on recent state tests. Math scores ranged from 9 to $11 \%$ proficient or advanced on the Pennsylvania System of School Assessment (PSSA) compared to $61 \%$ statewide. English scores ranged from 11 to $21 \%$ proficient or advanced on the PSSA compared to $42 \%$ statewide. In science, students fared slightly better at 6-34\% proficient or advanced, but still far below the 68\% statewide average (Pennsylvania Future Ready Index 2018). Though we, the authors, acknowledge the problematic nature of accountability through high stakes testing like Pennsylvania's PSSAs, they are part of the entanglement. Educators must interact with and respond to these types of tests that have very real consequences for teachers, administrators, and schools. These consequences can include limiting or eliminating the time for science (Au 2011); limiting physical resources for science (Spillane, Diamond, Walker, Halverson, and Jita 2001); or creating local policies focused on the improvement of test scores instead of reform-based policies (Bateman 2019). The state of Pennsylvania has yet to adopt the Next Generation Science Standards (NGSS), instead relying on a set of standards from 2002 that curtail the development of agential literacy by listing knowledge and skills focused on recall and identification that 
are often irrelevant for urban contexts, rather than emphasizing process-based science practices.

Each of these components-housing inequities, urban heat island effects, and lowperforming schools-is intra-acting in the Hunting Park community. They are also part of the city of Philadelphia and the governmental oversight it wields over them. The city's Office of Sustainability recognized the environmental injustices in Hunting Park, particularly the ties to racial and socioeconomic inequities that marginalize this community. In a program called Beat the Heat, the Office of Sustainability partnered with the community to learn and develop strategies that are implementable and will decrease extreme heat effects in the area, such as planting trees and providing air-conditioned places like libraries and community centers to escape the heat. The community has been included in the response-ability (Barad 2007) of helping establish environmental justice within the neighborhood where they are serving as educators, advocates, and scientists. The government, by acknowledging the community's ways of knowing, grows alongside the community (Roth 2021). However, it must be noted that these strategies maintain an anthropogenic focus and fail to highlight long-term needs for rectifying this problem beyond infrastructure. One such long-term need is to provide formal science education in the area of response-ability.

As part of the Beat the Heat project (Philadelphia Office of Sustainability 2019), the city has partnered with local schools as sites for recruitment of participants and acknowledged the need for air conditioning in mediating the effects of heat crises, but makes no obvious connections to the need for improving scientific literacy in the curriculum of the School District of Philadelphia. Recently, the School District has begun to utilize the Next Generation Science Standards (NGSS) in its curriculum, but this comes on the heels of years of using the poorly constructed Pennsylvania State Standards, crafted in 2002 as a response to NCLB. The 2002 Pennsylvania State Standards list content to be learned in discrete packages that often result in teachers emphasizing vocabulary memorization and assigning linear "cookbook" style experiments to arrive at right answers (Bateman 2019) - the opposite of engagement in scientific practices advocated for by the NGSS. Though the NGSS are far from ideal for posthuman ideas of science education, they provide forward progress in agential literacy. Schools in Pennsylvania are also still being held accountable to the PSSA tests in $4^{\text {th }}$ and $8^{\text {th }}$ grade and the Keystone Biology exam in high school, which are aligned with the 2002 Pennsylvania State Standards and Assessment Anchors, not the newly adopted NGSS. The continued use of the PSSA tests and the Keystone Biology exam, as well as introduction of the NGSS are part of the entanglement the community of Hunting Park must grow in as they work toward environmental justice.

Learning science is not the exclusive property of formal education. Communities of all shapes, sizes, and purposes can come together to grow. In Hunting Park, this included adult residents, members of the government, and academic scientists from multiple universities, each entangled with the other, consciously or not. However, by not incorporating formal science education into this project an unproductive tension has been created within the entanglement in which K-12 students learn one way of being scientifically literate at school and another through their community.

It is critically important that we think about the myriad actors (human and more-thanhuman) entangled in the quest for environmental justice and post-Anthropogenic sustainability. We believe that adjusting science policy and opening locations of possibility outside formal education (Kayumova and Tippins 2021) are valiant, necessary steps, but not enough. As Wolff-Michael Roth (2015) advocates, we must rethink what it means to do schooling, especially within STEM fields. Educational policies that drive formal schooling 
need to release their hold on teaching and learning and craft locations of possibility in formal education for students and communities to grow agential literacy and become stewards of sustainable environments, rather than continue to let neoliberal policy dominate the intra-actions.

\section{Growing new entanglements in science education}

The case of Hunting Park exhibits how social inequity is woven into sustainability. The development of sustainability engineers who are conscious of entanglement is needed if we mean to rectify sustainability inequities. As Jeong, Sherman, and Tippins lay out elsewhere in this issue Homo sapiens must move from the subspecies sapiens to subspecies textilis and ensure that we know our interwoven existence. These scholars argue that we need humans to be decentered, but to do so, we also need to center human action within the entanglement regarding science education, asking ourselves what action, what responseability can happen to help move us toward developing sustainability engineers with agential literacy through equitable science education? Here, we suggest science education practices that can help move us toward Homo sapiens textilus.

As we see in the Hunting Park example, science education, especially in the US, is not meeting the needs of the communities it is meant to serve. The neoliberal history of the education system perpetuates anthropogenic views of science education and by doing so has created binaries of difference; of sexualized, racialized, and naturalized "others:" marginalizing any group that is not white, straight, wealthy, or male (Steele 2018). Individuals who do not fit into the category of white, male, heterosexual, and middle class, are relegated to a marginalized position of inferiority. Accordingly, research suggests that being a part of a marginalized, or othered group can hamper career success and productivity (Yoder and Matheis 2016). To shift to an agential literacy approach to science education, the community needs to experience paradigm shifts (Kuhn 2012) in the community writ large. From teachers to policy makers, resource companies, scientists, parents, and students, a new perspective on what and who science is for needs to come to the forefront. The science education community is becoming in the post-Anthropocene acutely aware of its entanglement being something bigger than Homo sapiens.

Seeing humans as just one part of a more important, larger thing is not a novel idea, indigenous peoples have traditionally held this view in their interactions with the world. Indigenous ways of knowing position humans as in nature, not outside of it (Medin and Bang 2014), entangled in the daily ebb and flow of the world. However, colonialism has pushed these ways of not just doing science, but being, out of mainstream communities. Settled expectations shape science education (Bang and Marin 2015) as white privilege shapes what counts as science and perpetuates white, Western ideas. As a result, students from non-dominant communities often do not have their voices and ways of knowing heard in traditional science classrooms (Gutiérrez and Calabrese Barton 2015). Megan Bang and Ananda Marin (2015) advocate bringing Indigenous Ways of Knowing into science education to develop nature-culture relations, an idea that blends into de-centered human perspectives on science education. As Kayumova and Tippins (2021) posit, the ongoing silencing of Indigenous Ways of Knowing through colonial settler expectations of science education destroys the agency of non-white, non-dominant cultures. To counter the historical binary between Indigenous Ways of Knowing and white, Eurocentric science, educational policies will need to create locations of possibility that not only establish critical 
response-ability for BIPOC students, but for their white counterparts for whom science has been white-washed and territorialized as a linear process. Elizabeth Mack and colleagues (2012) show many ways this can be done in partnership between reservations and informal learning environments but question the extension to rigid formal education.

Opening these locations of possibility require political, and resulting curricular, disruptions to the dominant educational narrative. We must push back on the dominant narratives that determine what counts as science literacy and who decides what counts. As seen in the Hunting Park example, science education, particularly in the urban centers that are home to many non-dominant communities, is often an afterthought in formal education, a result of existing national and local policies that either force neo-liberal ideologies of education or devalue science education in favor of math and reading. ESSA relegated control of accountability back to states, but has, until the current COVID-19 pandemic, not resulted in changes to testing-centered accountability. We saw states, even if temporarily, eliminate their testing measures in 2020. Colleges stopped requiring SAT and ACT scores in their admission packages. These changes are temporary but reveal the possibility that the tests do not need to exist. Many other political roadblocks still need to be removed: inequitable standards, funding systems, teacher education guidelines, and more. These types of changes need to happen at the local, state, and national levels to allow science classrooms to become response-able environments for students to learn to de-center themselves and become sustainability engineers.

Recent innovations in science education practices, such as Ambitious Science Teaching (AST; Windschitl, Thompson, and Braaten 2018), include focusing on engaging students in learning science through explaining phenomena. AST has been used to engage in more authentic problem solving with BIPOC student communities in locally relevant issues. Jessica Thompson and colleagues (2020) outline principles for engaging in racial justice for BIPOC communities through AST, but these practices still center humans as observers and actors, rather than as part of the entanglement with non-human actors. For example, in the resources available on the AST website (University of Washington n.d.), available environmental phenomena include exploration of algal blooms and their impact on humans further up the food chain. Though we do not challenge the scientific knowledge gained through the study of this phenomenon, we make note of the place humans retain at the center of the learning. Examples of non-human centric phenomena must be found and made available to the average science teacher if we want to continue to shift to post-Anthropogenic ethics of mattering. Mack and colleagues (2012) stress the importance of involving the community as a resource in designing science learning opportunities to avoid an often tokenistic approach to community knowledge. Partnerships like those of Mack and colleagues, Kayumova and Tippins, and Philadelphia and Hunting Park show that it is within our grasp to give space for non-dominant communities to have a voice in what counts as science. However, the political actors, often white, affluent men, with institutionalized power, will need to think in new ways to allow these changes to manifest.

Another curricular shift needed to approach this post-Anthropogenic perspective of sustainability through agential literacy includes remarrying the content in STEM. STEM has become an educational buzzword that has been co-opted into meaning just the teaching of science, technology, engineering, or math, rather than an integration of them. Technology and engineering have a key role to play in sustainability engineering; therefore, we need to think about how STEM is integrated into classrooms and schools. Carla Johnson (2012) describes four key premises of STEM: natural integration of STEM disciplines; inclusion of all students regardless of ability; deep change to school practices and norms; and policies that integrate STEM across all levels of the educational system. Here STEM education 
must be for all students, regardless of ability, zip code, or any other demographic. Successful STEM integration can be achieved, but requires rethinking science education to address real-world problems and solutions with real-world problems to solve, preparing students to communicate with others, and motivating students to engage (Morrison, Rother McDuffie, and French 2015). Moving in these directions will provide students opportunities but does not guarantee agential literacy for sustainability engineering.

For the teachers in our Hunting Park example, creating agential literacy can occur through curricular shifts away from laundry-list models of standards to the NGSS and phenomenon-based practices like AST, but they will need resources and education not often afforded to pre-service teachers in their certification programs. Here, we are tying the curricular and political disruptions together-policies governing both what can happen in science classrooms and the way those things happen need to change within teacher education. One such proposition would be to re-think the apprenticeship models of teacher education (practicum and student teaching). The traditional separations between higher education classwork in teacher education and the real-world practice should be collapsed so that teacher educators, mentor teachers, pre-service teachers, and administrators are in conversation as pre-service teachers grow into full members of the teaching community (McDonald, Bateman, and McCausland 2020). Done with a mindset in which all parties are engaged in decentering humans in sustainable education that works to dismantle racial and cultural injustice can help us move curriculum and policies toward a more equitable educational experience where humans are more than observers (Barad 2003), and students engage in the ethics of mattering that does not include themselves (Jeong, King, Pauli, Sell, and Steele 2020).

\section{Entanglement for survival}

Reimagining science education is no longer an option, but a necessity. Schools are not providing equitable opportunities for students to access agential literacy in pursuit of sustainability engineering. Our post-Anthropocene hopes lie in rethinking schools as places of science education that are not tied to standards, tests, and other neo-liberal ideas of education. We need to provide students with a perspective of the world that de-centers the human, and it allows them to see that they are part of a larger entanglement. Like the bald eagle, we possess the capacity to shift and change our actions in response to the environment. Like the beaver, we can engineer in ways that advance us but can damage others. Students need to use agential literacy to become sustainability engineers, but with a moral responsibility that comes with our access to innovation and technology. We cannot sacrifice other actors in the entanglement to ensure our own survival.

\section{References}

Anderson, K. (2012). Science education and test-based accountability: Reviewing their relationship and exploring implications for future policy. Science Education, 96(1), 104-129. https://doi.org/10.1002/ sce. 20464.

$\mathrm{Au}, \mathrm{W}$. (2011). Teaching under the new Taylorism: High-stakes testing and the standardization of the 21st century curriculum. Journal of Curriculum Studies, 43(1), 25-45. https://doi.org/10.1080/00220272. 2010.521261 
Bang, M., \& Marin, A. (2015). Nature-culture constructs in science learning: Human/non-human agency and intentionality. Journal of Research in Science Teaching, 52(4), 530-544. https://doi.org/10.1002/ tea. 21204

Barad, K. (2000). Reconceiving scientific literacy as agential literacy: or learning how to intra-act responsibly within the world. In R. Reid \& S. Traweek (Eds.), Doing science + culture (pp. 221-258). Routledge.

Barad, K. (2001). Scientific literacy $\rightarrow$ agential literacy $=$ (learning + doing) science responsibly. In M. Mayberry, B. Subramaniam, \& L. H. Weasel (Eds.), Feminist science studies: A new generation (pp. 226-246). Psychology Press. https://doi.org/10.4324/9780203614266-29

Barad, K. (2003). Posthumanist performativity: Toward an understanding of how matter comes to matter. Signs: Journal of Women in Culture and Society, 28(3), 801-831. https://doi.org/10.1086/345321

Barad, K. (2007). Meeting the universe halfway: Quantum physics and the entanglement of matter and meaning. Duke University Press. https://doi.org/10.1515/9780822388128

Bateman, K. M. (2019). Assembling policy dilemmas: science teacher responses to educational policy. In [Unpublished doctoral dissertation]. School of Education, The Pennsylvania State University, State College, PA.

Berryman, A. A. (1992). The origins and evolution of predator-prey theory. Ecology, 73(5), 1530-1535. https://doi.org/10.2307/1940005

Biersack, A. (2006). Reimagining political ecology: Culture/power/history/nature. In A. Biersack \& J. B. Greenberg (Eds.), Reimagining political ecology (pp. 3-40). Duke University Press. https://doi. org/https://doi.org/10.1215/9780822388142-001

Brandt, C. B. (2008). Discursive geographies in science: Space, identity, and scientific discourse among indigenous women in higher education. Cultural Studies of Science Education, 3, 703-730. https:// doi.org/10.1007/s11422-007-9075-8

Darling-Hammond, L. (2007). Evaluating "No Child Left Behind.” The Nation, 284(20), 11.

Davidson, A., \& Gray, R. (2018). Model-based inquiry. Retrieved October 12, 2020, from https://sites. google.com/view/modelbasedinquiry/home?authuser $=0$

Gutiérrez, K. D., \& Calabrese Barton, A. (2015). The possibilities and limits of the structure-Agency dialectic in advancing science for all. Journal of Research in Science Teaching, 52, 574-583. https://doi.org/10.1002/tea.21229

Hillier, A. E. (2003). Redlining and the home owners' loan corporation. Journal of Urban History, 29, 394-420. https://doi.org/10.1177/0096144203029004002

Hondula, D. M., Davis, R. E., Leisten, M. J., Saha, M. V., Veazey, L. M., \& Wegner, C. R. (2012). Finescale spatial variability of heat-related mortality in Philadelphia County, USA, from 1983-2008: A case-series analysis. Environmental Health, 11(1), 1-11. https://doi.org/10.1186/1476-069X-11-16

Jeong, S., Britton, S., Haverkos, K., Kutner, M., Shume, T., \& Tippins, D. (2018). Composing new understandings of sustainability in the Anthropocene. Cultural Studies of Science Education, 13, 299-315. https://doi.org/10.1007/s11422-017-9829-X

Jeong, S., King, G., Pauli, D., Sell, C., \& Steele, D. (2020). Conceptualizing multiplicities of scientific literacy from five theoretical perspectives. In T. Teo, A. L. Tan, \& Y. Ong (Eds.), Science education in the $21^{\text {st }}$ century (pp. 3-17). Springer. https://doi.org/10.1007/978-981-15-5155-0_1

Jeong, S., Sherman, B., \& Tippins, D. J. (2021). The Anthropocene as we know it: posthumanism, science education and scientific literacy as a path to sustainability. Cultural Studies of Science Education. https://doi.org/10.1007/s11422-021-10029-9.

Johnson, C. C. (2012). Letter from the editor: four key premises of STEM. School Science and Mathematics, 112(1), 1-2. https://doi.org/10.1111/j.1949-8594.2011.00115.x

Kayumova, S., \& Tippins, D. J. (2021). The quest for sustainable futures: designing transformative learning spaces with Black, Brown, and Latinx young people through critical response-ability. Cultural Studies of Science Education. https://doi.org/10.1007/s11422-021-10030-2.

Kuhn, T. S. (2012). The Structure of Scientific Revolutions. University of Chicago Press. https://doi.org/ 10.7208/chicago/9780226458144.001.0001

Locke, D., Hall, B., Grove, J. M., Pickett, S. T., Ogden, L. A., Aoki, C., Boone, C.G. \& O’Neil-Dunne, J. P. (2020, January 6). Residential housing segregation and urban tree canopy in 37 US Cities. Center for Open Science. https://doi.org/10.31235/osf.io/97zcs

Lovelock, J. (2015). A Rough Ride to the Future. Overlook Press.

Mack, E., Augare, H., Cloud-Jones, L. D., Davíd, D., Gaddie, H. Q., Honey, R. E., Kawagley, A. O., Plume-Weatherwax, M. L., Lone Fight, L., Meier, G., Pete, T., Rattling Leaf, J., Scout, R. F., Sachatello-Sawyer, B., Shibata, H., Valdez, S., \& Wippert, R. (2012). Effective practices for creating transformative informal science education programs grounded in Native ways of knowing. Cultural Studies of Science Education, 7(1), 49-70. https://doi.org/10.1007/s11422-011-9374-y 
McDonald, S., Bateman, K., \& McCausland, J. (2020). Practice-embedded science teaching methods. In D. Stroupe, K. Hammerness, \& S. McDonald (Eds.), Preparing Science Teachers through PracticeBased Teacher Education (pp. 171-186). Harvard Education Press.

Medin, D. L., \& Bang, M. (2014). Who's asking?: Native science, western science, and science education. MIT Press. https://doi.org/10.7551/mitpress/9755.001.0001

Morrison, J., Roth McDuffie, A., \& French, B. (2015). Identifying key components of teaching and learning in a STEM school. School Science and Mathematics, 115(5), 244-255. https://doi.org/10. $1111 /$ ssm. 12126

Pennsylvania Department of Education. (2018). Future Ready PA Index. Retrieved November 03, 2020, from https://futurereadypa.org/

Philadelphia Office of Sustainability. (2019). Beat the heat Hunting Park: A community relief plan [Pamphlet]. Philadelphia, PA: City of Philadelphia. Retrieved from: https://www.phila.gov/media/20190 719092954/HP_R8print-1.pdf

Roth, W. (2015). Schooling is the problem: A plaidoyer for its deinstitutionalization. Canadian Journal of Science, Mathematics and Technology Education, 15(3), 315-331. https://doi.org/10.1080/14926156. 2015.1051672.

Roth, W.-M. (2019). Transactional psychology of education: Toward the social in a strong sense. Springer. https://doi.org/10.1007/978-3-030-04242-4

Roth, W.-M. (2021). Gardener-becoming-tree, tree-becoming-gardener: Growing-together as a metaphor for thinking about learning and development. Cultural Studies of Science Education. https://doi.org/10. 1007/s 11422-021-10032-0.

Southerland, S. A., Smith, L. K., Sowell, S. P., \& Kittleson, J. M. (2007). Resisting unlearning: Understanding science education's response to the United States' national accountability movement. Review of Research in Education, 31(1), 45-77. https://doi.org/10.3102/0091732X07300046045

Spillane, J. P., Diamond, J. B., Walker, L. J., Halverson, R., \& Jita, L. (2001). Urban school leadership for elementary science instruction: Identifying and activating resources in an undervalued school subject. Journal of Research in Science Teaching, 38, 918-940. https://doi.org/10.1002/tea.1039

Steele, D. (2018). "It's like having to go back into the closet everyday": A narrative inquiry examining the impacts heteronormativity and heterosexism have on the experiences of gay men in STEM majors (Doctoral dissertation). Retrieved from University of Georgia Library.

University of Washington. (n.d.). Tools for Ambitious Science Teaching. Retrieved November 04, 2020, from https://ambitiousscienceteaching.org/tools/

Thompson, J., Maywer, K., Johnson, H., Scipio, D., \& Leuhmann, A. (2020). From responsive teaching toward developing culturally and linguistically sustaining science teaching practices. In D. Stroupe, K. Hammerness, \& S. McDonald (Eds.), Preparing science teachers through practice-based teacher education (pp. 45-61). Harvard Education Press.

Thompson, N., \& Tippins, D. (2013). Envisioning science teacher preparation for 21st century classrooms: Some tensions. In N. Mansour (Ed.), Science education for diversity in a knowledge society (pp 231249). Springer. https://doi.org/10.1007/978-94-007-4563-6_11

Weber, S., Sadoff, N., Zell, E., \& de Sherbinin, A. (2015). Policy-relevant indicators for mapping the vulnerability of urban populations to extreme heat events: A case study of Philadelphia. Applied Geography, 63, 231-243. https://doi.org/10.1016/j.apgeog.2015.07.006

Windschitl, M., Thompson, J., \& Braaten, M. (2018). Ambitious Science Teaching. Harvard Education Press.

Yoder, J. B., \& Matheis, A. (2016). Queer in STEM: Workplace experiences reported in a national survey of LGBTQA individuals in science, technology, engineering, and mathematics careers. Journal of Homosexuality, 63, 1-27. https://doi.org/10.1080/00918369.2015.1078632

Publisher's Note Springer Nature remains neutral with regard to jurisdictional claims in published maps and institutional affiliations.

Kathryn M. Bateman is a postdoctoral fellow in the Department of Psychology at Temple University in Philadelphia. She obtained her PhD from The Pennsylvania State University in Curriculum \& Instruction: Science Education. Her research is embedded in the everyday practices of teachers through a lens of postmodern philosophy with a goal of advocacy for equitable education. This research is situated at the intersection of geoscience education, educational policy, and teacher education. Bateman strongly believes in science teachers as stewards of environmental justice through the development of research-based practices that center the needs, knowledge, and natural scientific curiosity of students in all classrooms. 
David Steele is a STEM Education faculty member at Alder Graduate School of Education in Redwood City, CA. His research focuses on expanding access to STEM fields for all students, with an emphasis on members of the LGBTQ+ community.

Chelsea M. Sexton is a doctoral student in the Department of Mathematics and Science Education at the University of Georgia. Her research interests include education for sustainability, environmental education, science literacy, science teacher education, and innovation in research methods. 